\title{
Manejo de Plantas Daninhas em Cana-Crua ${ }^{1}$
}

\author{
Weed Management in Raw Sugarcane
}
FERREIRA, E.A. ${ }^{2}$; PROCÓPIO, S.O. ${ }^{3}$; GALON, L. ${ }^{4}$; FRANCA, A.C. ${ }^{5}$; CONCENÇO, G. ${ }^{6}$; SILVA, A.A. ${ }^{7}$; ASPIAZU, I. ${ }^{8}$; SILVA, A.F. ${ }^{9}$, TIRONI, S.P. ${ }^{9}$ e ROCHA, P.R.R. ${ }^{9}$

\begin{abstract}
RESUMO - Nos últimos anos, o processo de colheita da cana-de-açúcar vem sendo modificado, passando da tradicional queima do canavial para a colheita da cana-crua, seja por imposições da legislação ou conscientização ambiental e também por pressões da sociedade. A adoção desse novo sistema de colheita da cana-de-açúcar tem resultado em importantes modificações nas técnicas de cultivo, como o uso de maiores espaçamentos entre as linhas e a deposição de palha à superficie do solo, as quais influenciam diretamente a ocorrência e o manejo de plantas daninhas e a fertilidade dos solos. Mudanças da flora têm sido observadas em áreas cultivadas com a cana-crua em consequência do favorecimento de espécies com maior capacidade de germinação sob espessa cobertura de palha, em comparação com outras que têm a germinação impedida por ação física ou alelopática da palhada. Além disso, herbicidas utilizados em pré-emergência nessa cultura têm apresentado reduções na sua eficácia, pelo fato de que grande parte deles fica retida na palha e não atinge o solo na concentração necessária para o controle das plantas daninhas. Nesta revisão foram descritos os principais resultados envolvendo a pesquisa relacionada ao manejo de plantas daninhas em áreas com cana-crua, com o objetivo de disponibilizar informações aos pesquisadores para implementar técnicas e pesquisas no desenvolvimento do manejo integrado de comunidades infestantes na cultura da cana-de-açúcar. Os resultados mostram que há possibilidade de redução da dependência do uso de herbicidas e melhoria real da qualidade dos solos como consequência do maior acúmulo da palha oriunda da colheita da cana-de-açúcar.
\end{abstract}

Palavras-chave: Saccharum spp., sustentabilidade, palha, cobertura morta.

\begin{abstract}
In the last years, the sugarcane harvesting process has undergone changes imposed by law, environmental awareness or social pressure, leading to the exclusion of the traditional slash and burn before harvesting and inclusion of crude sugarcane harvest. This process is denominated crude harvesting. The adoption of this new harvesting system promoted alterations in the entire sugarcane tillage system, including wider row spacing and the formation of a mulching layer due to the deposition of sugarcane residues on the soil surface. This new crop management system affects directly the weed dynamics in these areas and soil fertility as well. Weed shifting has been observed, producing weed species with higher germination and emergence capacity under a thicker straw layer, compared to those unable to germinate due to the physical or allellopathic action of the straw. In addition, pre-emergence herbicides are usually less efficient under this system due to their retention in the straw, not reaching the soil in sufficient concentrations to promote weed control. In this literature review, the major results involving weed management in crude sugarcane areas are described to provide information to researchers, extension workers, and farmers on how to improve sugarcane integrated weed management, mainly under this new harvesting process. The results show that reduction of herbicide dependence is feasible, leading to improved soil quality in these fields.
\end{abstract}

Keywords: Sacharum spp., sustainability, straw, mulching.

1 Recebido para publicação em 11.10.2009 e na forma revisada em 12.11.2010.

2 D.Sc., Bolsista PNPD (Capes) da Universidade Federal dos Vales do Jequitinhonha e Mucuri - UFVJM, Faculdade de Ciências Agrárias, Campus II - Rodovia MGT 367 - Km 583, no 5000, Bairro Alto da Jacuba, 39100-000 Diamantina-MG; <evanderalves@yahoo.com.br>; ${ }^{3}$ D.Sc., Pesquisador da Embrapa Tabuleiros Costeiros, 49025-040 Aracaju-SE, <procopio@cpatc.embrapa.br>; ${ }^{4}$ D.Sc., Prof ${ }^{-}$da Faculdade da Amazônia - FAMA, Vilhena-RO; ${ }^{5}$ D.Sc., Professor, UFVJM; ${ }^{6}$ Engo $^{-}$Agr ${ }^{\circ}$, D.Sc., Pesquisador da Valley; ${ }^{7}$ Professor Associado - DFT/UFV, Bolsista em Produtividade de Pesquisa do CNPq, $<$ aasilva@ufv.br>; ${ }^{8}$ Engo-Agr ${ }^{\circ}$, D.Sc., DFT/UFV; ${ }^{9}$ Doutoranda do Dep. de Fitotecnia, DFT/UFV. 


\section{INTRODUÇÃO}

A cana-de-açúcar foi introduzida no Brasil em 1553, sendo estabelecida de forma definitiva nas regiões Centro-Sul e Nordeste. Atualmente, o Brasil é o maior produtor de cana-de-açúcar do mundo, moendo aproximadamente 640 milhões de toneladas por ano. As regiões Sudeste com 60\% (somente o Estado de São Paulo contribui com 52\% dessa área) e Nordeste com $21 \%$ da área total plantada são as maiores produtoras do País. Nessas duas regiões, a produtividade média é de 78 e $55 \mathrm{t} \mathrm{ha}^{-1}$, respectivamente (IBGE, 2009). Há uma clara tendência de aumento da área cultivada com cana-de-açúcar no Brasil.

$\mathrm{Na}$ composição do custo de produção da cana-de-açúcar, os gastos com o controle das plantas daninhas são de grande importância. Segundo Kuva et al. (2003), a interferência proporcionada pelas plantas daninhas acarreta redução significativa no rendimento da cultura, além de proporcionar outros aspectos negativos, como decréscimo da longevidade do canavial, redução da qualidade industrial da matéria-prima e dificuldade nas operações de colheita e transporte. Dessa forma, é evidente a necessidade de estratégias eficientes no controle das comunidades infestantes da cultura.

O processo de colheita precedido da queima do canavial está sendo substituído pela colheita da cana-crua, por imposições da legislação e pela consciência ambiental que se amadurece na sociedade brasileira. $\mathrm{O}$ manejo de plantas daninhas após a colheita da canacrua, assim como as propriedades físicas, químicas e biológicas do solo, têm sido alterados, sendo necessária a obtenção de mais informações científicas a respeito dessa nova tecnologia. A adoção desse sistema de colheita tem resultado em modificações nas técnicas de cultivo, como o uso de maiores espaçamentos entre linhas e a deposição de palha sobre o solo, que influenciam diretamente a ocorrência e o manejo de plantas daninhas (Velini \& Negrisoli, 2000).

Alguns benefícios agronômicos - como diminuição de processos erosivos, melhor conservação da umidade do solo, melhor reciclagem de nutrientes, aumento da matéria orgânica e da atividade microbiana do solo, melhoria das propriedades físicas e químicas do solo, diminuição da infestação de plantas daninhas, além da redução das perdas de açúcares via exsudação dos colmos durante e/ou logo após a queima - são vantagens observadas no sistema de colheita cana-crua (Velini \& Negrisoli, 2000). No entanto, podem ser citados alguns fatores desfavoráveis da adoção dessa tecnologia, como: dificuldade na brotação da maioria das variedades de cana-de-açúcar sob a palhada, aumento de pragas de solo que atacam a cultura, acréscimos nas doses dos fertilizantes nitrogenados, danos ao crescimento da cana em locais frios, manutenção de excesso de umidade em áreas mais baixas e limitação da aplicação de herbicidas para o período diurno, quando a presença das plantas daninhas é facilmente detectada (com exceção da implantação da "agricultura de precisão" (Correia \& Rezende, 2002).

\section{Controle de plantas daninhas pela palhada}

A palhada da cana-de-açúcar preservada proporciona cobertura do solo, o que dificulta a emergência de plantas daninhas, pois reduz a penetração de luz no solo. Pode ocorrer também a liberação de exsudados pela palha, que apresentam efeitos alelopáticos sobre a germinação de propágulos de plantas daninhas (Correia \& Rezende, 2002; Silva et al., 2003), Segundo Pitelli \& Durigan (2001), o efeito físico não se restringe apenas ao impedimento da passagem quantitativa e qualitativa da radiação solar, mas também a amenização da amplitude de variação térmica e da variação da umidade na camada superficial do solo. Segundo esses autores, outro importante efeito da palhada é o biológico, com a manutenção de uma comunidade microbiana que pode atuar na sobrevivência de sementes e plântulas das plantas daninhas.

Toledo et al. (2005), em estudo realizado no México, comparando áreas conduzidas nos sistemas de cana-crua com cana queimada, relataram que o primeiro sistema enfrentou menor agressividade das plantas daninhas em relação à cultura, maior produção de biomassa (colmos maiores, mais grossos e em maior quantidade), maior pureza da garapa e maior produção de açúcar. No solo, foram observadas diferenças nos teores de matéria orgânica, nitrogênio, fósforo e potássio e no $\mathrm{pH}$. A análise 
econômica mostrou renda muito maior no sistema de cana-crua quando comparado ao modelo tradicional. Núñez \& Spaans (2008), em estudo similar, comparando os dois sistemas, no Equador, observaram que o custo de controle das plantas daninhas foi $35 \%$ menor após a colheita pelo sistema de cana-crua.

Velini \& Negrisoli (2000) observaram que a palha da cana-de-açúcar reduziu drasticamente a variação da temperatura do solo a $1 \mathrm{e}$ a $5 \mathrm{~cm}$ de profundidade. Segundo esses autores, esse efeito contribui de modo decisivo para a redução da germinação de plantas daninhas de áreas de cana-crua, pois é sabido que a amplitude térmica é um dos componentes mais importantes na promoção da germinação das sementes de muitas espécies.

Para melhor efeito da cobertura morta sobre as plantas daninhas, três fatores são primordiais: quantidade $\left(\mathrm{t} \mathrm{ha}^{-1}\right)$, densidade $\mathrm{e}$ uniformidade de distribuição de palha da canade-açúcar no solo. As Tabelas 1 e 2 mostram as principais plantas daninhas presentes em áreas de colheita de cana-de-açúcar crua, em relação à quantidade de resíduos deixados no campo. Observa-se que, ao aumentar a quantidade de palha deixada sobre o solo, menor é a densidade de todas as espécies infestantes da lavoura canavieira (Tabela 1).

A quantidade de palha deixada após a colheita do canavial influencia o aparecimento de determinada espécie, ou seja, quando se alterou a quantidade de palha de 1-5 para
5-15 t ha ${ }^{-1}$ houve pequena alteração das espécies infestantes da área (Tabela 2). No entanto,

Tabela 2 - Principais plantas daninhas infestantes de canaviais em relação à quantidade de palhada na área

\begin{tabular}{|c|c|}
\hline $\begin{array}{l}\text { Quantidade de } \\
\text { palhada }\left(\mathrm{t} \mathrm{ha}^{-1}\right)\end{array}$ & Plantas daninhas presentes \\
\hline $1-5$ & $\begin{array}{l}\text { Cyperus rotundus } \\
\text { Cynodon dactylon } \\
\text { Brachiaria plantaginea } \\
\text { Brachiaria decumbens } \\
\text { Cenchrus echinatus } \\
\text { Chloris polydactyla } \\
\text { Digitaria insularis } \\
\text { Digitaria horizontalis } \\
\text { Digitaria sanguinalis } \\
\text { Eleusine indica } \\
\text { Panicum maximum } \\
\text { Rottboellia exaltata }\end{array}$ \\
\hline $5-15$ & $\begin{array}{l}\text { Cyperus rotundus } \\
\text { Cynodon dactylon } \\
\text { Digitaria insularis } \\
\text { Ipomoea acuminata } \\
\text { Ipomoea purpurea } \\
\text { Merremia cissoides } \\
\text { Sida cordifolia } \\
\text { Sida glaziovii } \\
\text { Rottboellia exaltata }\end{array}$ \\
\hline Maior que 15 & $\begin{array}{l}\text { Euphorbia heterophylla } \\
\text { Coniza bonariensis } \\
\text { Pyrostegia venusta }\end{array}$ \\
\hline
\end{tabular}

Fonte: Arévalo (1998).

Tabela 1 - Número de plântulas emergidas de quatro espécies daninhas antes e após a remoção da cobertura de palha de cana-de-açúcar (var. RB 82-5336)

\begin{tabular}{|c|c|c|c|c|c|c|c|c|}
\hline \multirow{2}{*}{$\begin{array}{c}\text { Quantidade } \\
\text { de palha } \\
\left(\mathrm{t} \mathrm{ha}^{-1}\right)\end{array}$} & \multicolumn{9}{|c|}{ Plântulas emersas (número 0,5 $\mathrm{m}^{-2}$ ) } \\
\cline { 2 - 9 } & \multicolumn{2}{|c|}{ Sida rhombifolia } & \multicolumn{2}{|c|}{ Euphorbia heterophylla } & \multicolumn{2}{c|}{ Bidens pilosa } & \multicolumn{2}{c|}{ Ipomoea grandifolia } \\
\cline { 2 - 9 } & A.R. & Ap. R. & A.R. & Ap. R. & A.R. & Ap. R. & A.R. & Ap. R. \\
\hline 0 & 184,50 & 42,75 & 47,25 & 17,00 & 41,75 & 13,25 & 30,00 & 26,50 \\
\hline 2 & 144,75 & 60,25 & 50,25 & 16,25 & 72,00 & 20,50 & 52,25 & 25,50 \\
\hline 4 & 132,50 & 143,00 & 48,50 & 13,00 & 85,75 & 21,50 & 50,25 & 35,00 \\
\hline 6 & 58,75 & 107,50 & 57,25 & 20,50 & 80,75 & 32,00 & 52,25 & 45,50 \\
\hline 8 & 40,50 & 100,75 & 45,50 & 26,50 & 51,75 & 18,00 & 52,50 & 43,50 \\
\hline 10 & 26,25 & 102,00 & 56,50 & 47,75 & 40,00 & 20,50 & 47,75 & 40,00 \\
\hline 15 & 5,00 & 21,75 & 51,25 & 43,75 & 9,75 & 32,50 & 19,50 & 48,25 \\
\hline
\end{tabular}

A.R. - antes da remoção; Ap. R. - após a remoção.

Fonte: Martins et al. (1999). 
ao alterar para mais que $15 \mathrm{t} \mathrm{ha}^{-1}$ de palhada, surgiram diferentes espécies que até então não haviam aparecido nas menores quantidades de palha. Esse fato pode ser explicado em razão de que determinadas espécies daninhas só emergem com menor quantidade de luz disponivel, ou seja, são chamadas de plantas fotoblásticas negativas (Procópio et al., 2003).

As quantidades de palha formadas são variáveis, dependendo principalmente da variedade de cana-de-açúcar, das condições climáticas, da nutrição da cultura e dos tratos culturais, podendo ultrapassar $20 \mathrm{t} \mathrm{ha}^{-1}$. Em áreas em que se irá adotar o sistema de colheita de cana-crua, é preferivel optar pelo cultivo de variedades que produzam grande quantidade de palha e também por plantas que tenham adequado suprimento nutricional e ótima resistência ou tolerância a pragas e doenças (Procópio et al., 2003).

Arévalo (1998) relata que é possivel fazer generalizações práticas, relacionadas com a infestação de plantas daninhas, que começam a emergir ao redor dos 30 a 50 dias após a colheita da cana-crua, em função da quantidade de resíduos da colheita. Conforme o autor, em quantidades de resíduos maiores que $15 \mathrm{t} \mathrm{ha}^{-1}$ ocorre redução da infestação da área por plantas daninhas.

De acordo com Velini \& Negrisoli (2000), a irregularidade da distribuição da cobertura da palha permite que a germinação de sementes de plantas daninhas ocorra em determinados pontos da lavoura. Desse modo, para que o controle de espécies sensiveis à cobertura com palha seja maximizado, é necessário que o resíduo esteja presente na quantidade necessária e regularmente distribuído sobre o solo. Esses autores ressaltam ainda que a germinação das plantas daninhas ocorre em função das características de ambientes de dimensões bastante reduzidas $\left(\mathrm{cm}^{2}\right.$ ou $\left.\mathrm{mm}^{2}\right)$, e é nessa escala que a irregularidade ou regularidade da camada de palha deve ser avaliada.

\section{Mudança na população de plantas daninhas}

Um dos pontos-chave no processo produtivo da cana-de-açúcar é a interferência imposta pelas plantas daninhas ao competir com a cultura por nutrientes, água e luz, dificultar a colheita, diminuir a qualidade da produção e reduzir a longevidade do canavial (Procópio et al., 2003). A flora infestante da cana-deaçúcar é altamente específica (Mascarenhas et al., 1995), e a implementação da colheita mecanizada está mudando a composição da comunidade infestante (Azania et al., 2002).

Correia \& Durigan (2004) verificaram que a palha de cana mantida na superficie do solo interfere na dormência, germinação e mortalidade das sementes de plantas daninhas, provocando modificações da comunidade infestante. Essas mudanças, no entanto, são muito específicas e dinâmicas, pois dependem da quantidade de palha e, principalmente, da espécie daninha, que pode ser favorecida ou não pela cobertura morta.

Estudos demonstram que algumas espécies de plantas daninhas, predominantes na cultura de cana-de-açúcar, apresentam comportamento diferenciado em função da quantidade de palha depositada sobre o solo (Medina Melendez, 1990; Martins et al., 1999; Velini et al., 2000). Plantas daninhas consideradas importantes nessa cultura, como Brachiaria decumbens, $B$. plantaginea, Panicum maximum e Digitaria horizontalis, podem ser eficientemente controladas pela presença de $15 \mathrm{t} \mathrm{ha}^{-1}$ de palha (Velini et al., 2000). O mesmo não ocorre com Ipomoea grandifolia e Euphorbia heterophylla, cujo controle pela palha é deficiente (Martins et al., 1999), e provavelmente isso ocorra em função de essas espécies serem fotoblásticas negativas.

Monquero et al. (2008), avaliando a infestação de plantas daninhas em diferentes sistemas de colheita de cana-de-açúcar, observaram que os talhões com cana-crua possuíam menor potencial de infestação em relação aos talhões de cana-queimada.

Oliveira \& Freitas (2008), em um levantamento fitossociológico de plantas daninhas em áreas de produção de cana-crua na região Norte Fluminense, identificaram 95 espécies de plantas daninhas, distribuídas em 74 gêneros e em 30 famílias, sendo as famílias predominantes: Poaceae, seguida por Asteraceae, Euphorbiaceae, Malvaceae e Amarantaceae.

Lorenzi (1993) mencionou que a manutenção de aproximadamente $12 \mathrm{t} \mathrm{ha}^{-1} \mathrm{de}$ 
cobertura morta de cana na superfície do solo proporcionou o melhor controle das plantas daninhas $(100 \%)$, e, com a sua remoção total, não houve controle $(0 \%)$. O nivel de controle das plantas daninhas aumentou proporcionalmente à quantidade de palha deixada na superficie do solo. Assim, as principais espécies de plantas daninhas ocorrentes no referido trabalho foram: Portulaca oleracea, Amaranthus deflexus, Panicum maximum, Eleusine indica e Digitaria horizontalis. Em outro estudo, Medeiros \& Christoffoleti (2001) constataram que $B$. decumbens, B. plantaginea, Digitaria horizontalis e Panicum maximum apresentaram desenvolvimento reduzido nos tratamentos em que houve a presença de palha de cana, contrariamente ao das parcelas sem palha. Estes autores relataram também que, embora as espécies Euphorbia heterophylla e Ipomoea hederifolia tenham emergido nas parcelas sem palha, nas áreas com palha houve maior taxa de emergência dessas espécies.

Kuva et al. (2008), avaliando a correlação entre o banco de sementes na cultura da canacrua e a flora estabelecida neste agroecossistema, verificaram que o banco de sementes em áreas de cana-crua apresentavam em média 350 sementes $\mathrm{m}^{-2}$. Esses autores constataram maior predominância das espécies Amarantus spp., Cyperus spp., Cassia patellaria, Ipomoea spp., Chamaesyce hissopifolia, Sida spp. e Phylantus tenellus, porém com baixa correlação com o banco de sementes.

Correia \& Durigan (2004), trabalhando com emergência de plantas daninhas em solo coberto com palhada em condições de casa de vegetação, constataram redução da densidade populacional das espécies $B$. decumbens, Sida spinosa e Digitaria horizontalis (Tabela 5), mas não observaram variações na densidade de I. grandifolia, I. hederifolia e I. quamoclit (Tabela 5).

De acordo com os resultados observados na Tabela 5, o aumento da quantidade de palha de cana sobre o solo não ocasionou diferenciação no número de plantas do gênero Ipomoea estudadas por Correia \& Durigan (2004). Pode-se inferir que plantas desse gênero apresentam-se como fotoblásticas negativas, não requerendo grande intensidade luminosa para germinarem. Contudo, a redução da quantidade de palha tem diminuído o número de plantas das espécies estudadas, sendo possivel afirmar que essas plantas apresentam-se como fotoblásticas positivas (Tabela 6).

Segundo Durigan \& Correia (2004), o efeito físico da cobertura morta é muito importante na regulação da germinação e na taxa de sobrevivência das plântulas de algumas espécies de plantas daninhas. De acordo com Maciel et al. (2008), a presença da palhada da cana-de-açúcar proporcionou controle excelente das espécies Digitaria horizontalis e Brachiaria decumbens, mesmo na ausência de herbicida. Os efeitos sobre o processo germinativo podem ser exemplificados com a redução da germinação de sementes fotoblásticas positivas, pois estas requerem determinado comprimento de onda e também necessitam de grande amplitude térmica para inibir o processo germinativo. O efeito fisico da palha também reduz as chances de sobrevivência das plântulas com pequena quantidade de reservas nos diásporos (Pitelli \& Durigan, 2001).

\section{Controle químico em cana-crua}

O controle químico de plantas daninhas nas áreas de colheita de cana-crua deverá ser quase que totalmente realizado com aplicações de herbicidas em pós-emergência das plantas daninhas. Conforme Velini \& Negrisoli (2000), para melhor implantação do sistema de canacrua, são necessários novos herbicidas sistêmicos para uso em pós-emergência e seletivos à cultura, pois os que existem atualmente apresentam toxidez à cultura e eficiência limitada. Essa situação poderá ser amenizada com a introdução de variedades transgênicas resistentes ao herbicida glyphosate, por exemplo. Na Tabela 3 são apresentados os principais herbicidas a serem usados em cana-crua. Todavia, Velini \& Negrisoli (2000) relatam que, em áreas com alta infestação de plantas daninhas, menor crescimento da cultura e camada da palha pouco espessa, há necessidade da continuidade do uso de herbicidas com efeito residual para se controlar de maneira eficiente as plantas daninhas.

Para melhor avaliar a interceptação dos herbicidas aplicados em pré-emergência na palhada de cana-crua, Velini \& Negrisoli (2000) realizaram estudo com aplicação do corante 
Tabela 3 - Principais herbicidas e misturas utilizados no manejo de plantas daninhas em áreas de colheita de cana-crua

\begin{tabular}{|l|l|}
\hline \multicolumn{1}{|c|}{ Nome comum } & \multicolumn{1}{|c|}{ Tipo de aplicação } \\
\hline 2,4-D & Pós-emergência \\
\hline 2,4-D + Picloram & Pós-emergência \\
\hline Ametryn & Pós-emergência inicial \\
\hline Ametryn + Clomazone & Pós-emergência inicial \\
\hline Ametryn + trifloxysulfuron-sodium & Pós-emergência \\
\hline Amicarbazone & Pós-emergência \\
\hline Clomazone + Ametryn & Pós-emergência \\
\hline Clomazone + Hexazinone + Diuron & Pós-emergência \\
\hline Flazasulfuron & Pós-emergência \\
\hline Glyphosate & Pós-emergência, aplicação dirigida \\
\hline Glyphosate + 2,4-D & Pós-emergência, aplicação dirigida \\
\hline Halosulfuron & Pós-emergência \\
\hline Hexazinone + Diuron & Pós-emergência \\
\hline Imazapic & Pós-emergência \\
\hline Iodosulfuron-methyl & Pós-emergência \\
\hline MSMA & Pós-emergência, aplicação dirigida \\
\hline MSMA + Diuron & Pós-emergência, aplicação dirigida \\
\hline Paraquat & Pós-emergência, aplicação dirigida \\
\hline Paraquat + Diuron & Pós-emergência, aplicação dirigida \\
\hline
\end{tabular}

FDC-1 (simulando um herbicida), procurando determinar a porcentagem de interceptação deste por camadas de palha de $0,1,2,4,6,8$, 10 e $15 \mathrm{t} \mathrm{ha}^{-1}$. Utilizaram-se bicos XR 110.02 operando a 25 psi, com espaçamento de $0,5 \mathrm{~m}$ e velocidade de aplicação de $3,6 \mathrm{~km} \mathrm{~h}^{-1}$, proporcionando a aspersão de $195 \mathrm{~L} \mathrm{ha}^{-1}$ de calda herbicida. Os resultados indicaram que na camada de palha de $1 \mathrm{t} \mathrm{ha} \mathrm{a}^{-1}$ ocorreu a deposição de apenas $35,5 \%$ da calda pulverizada sobre o solo. Com 10 e $15 \mathrm{t} \mathrm{ha}^{-1}$, as porcentagens de interceptação da calda pela palha foram de 99,4 e 99,5\%, respectivamente.

Outra tendência vinda da adoção desse sistema de colheita são as aplicações dirigidas e localizadas de herbicidas, visto que, dependendo da barreira vegetal formada, a infestação pode ser muito pequena e pode se apresentar de caráter espaçado, não sendo econômica a aplicação de herbicidas em área total. Atualmente, aplicações dirigidas têm sido feitas principalmente em áreas onde se trabalha em pós-emergência em que ocorra efeito "guarda-chuva" da cultura, devido ao porte das plantas de cana-de-açúcar. Com isso, deve-se aumentar o uso de pulverizadores costais (pressurizados e/ou manuais), de pingentes e pistolas acopladas aos pulverizadores que permitam aplicar herbicidas somente no alvo. Deve-se considerar que, em áreas de canacrua onde a distribuição da palha se encontre muito irregular, recomenda-se adicionar um herbicida pré-emergente junto à calda de aplicação, para realizar a catação química (Velini et al., 2000).

Ozeki (1992) relata a possibilidade de aplicar herbicidas em pré-emergência no momento da colheita, utilizando-se um equipamento de pulverização acoplado à colheitadeira de cana-de-açúcar. Para ele, esse sistema apresentaria algumas vantagens, como: redução do custo operacional da aplicação de herbicidas, aproveitamento da umidade do solo devido à palhada e proteção pela palha contra a fotodecomposição do herbicida. Contudo, o sistema de cana-crua ocasiona aumento no teor de matéria orgânica do solo, em razão do grande acúmulo de palha. Esse acréscimo pode causar aumento da sorção de herbicidas no solo, limitando a eficiência e exigindo maiores doses, elevando o custo do tratamento e possibilitando a maior ocorrência de problemas ambientais.

Barbosa (1997) descreve uma experiência na usina Santa Elisa (SP) no manejo de plantas daninhas sob sistema de cana-crua. Segundo esse autor, a palhada tem contribuído com eficácia para o controle das plantas daninhas, permitindo redução no custo dessa operação em torno de $30 \%$, em comparação ao custo do controle em que a cana-de-açúcar continua sendo queimada. $\mathrm{O}$ autor registra ainda que, entre as diversas situações encontradas no manejo de plantas daninhas nesse novo sistema de colheita, as mais relevantes são: em relação às gramineas anuais e perenes provenientes de sementes, o controle da palhada é altamente eficaz e as infestações dessas espécies ocorrem quase que somente onde há "clareiras"; gramineas perenes já instaladas conseguem atravessar a palhada e se desenvolvem normalmente; e algumas espécies infestantes dicotiledôneas têm sido selecionadas neste sistema, principalmente plantas das famílias Cucurbitaceae e Euphorbiaceae, bem como espécies do gênero Ipomoea, extremamente agressivas e capazes de impossibilitar a colheita mecanizada ou encarecer o custo da colheita manual. Ressalta-se que as espécies pertencentes ao gênero Cyperus 
precisam ser controladas, pois elas podem apresentar atraso no seu desenvolvimento na presença da palhada, porém conseguem completá-lo e, assim, vão aumentando o banco de sementes do solo e tornar-se-ão futuro problema na lavoura canavieira.

De posse dessas informações, a usina Santa Elisa (SP) vem realizando o controle em pós-emergência das plantas daninhas e, em parceria com uma empresa de agrotóxicos e outra de tecnologia de aplicação, desenvolveu um equipamento para realizar operação de "catação química tratorizada", com aplicação do herbicida somente onde se observam plantas daninhas. Para isso, na saída do pulverizador foi instalado um sistema de saídas independentes para cada ponta de pulverização (bico), em pingentes. O operador, por meio de um comando eletrônico, aplica o herbicida apenas no local onde ocorre a infestação.

$\mathrm{Na}$ presença de até $10 \mathrm{tha}^{-1}$ de palha de cana-de-açúcar, o controle das plantas daninhas Senna obtusifolia, Ipomoea nil, I. hederifolia e I. grandifolia foi satisfatório quando aplicado o herbicida trifloxysulfuronsodium + ametryn, porém em quantidades maiores de palha ocorreu redução da ação desse herbicida no controle de plantas daninhas (Gravena et al., 2004).

Em outro estudo, observou-se que os herbicidas sulfentrazone e imazapic foram eficazes no controle de Cyperus rotundus apenas quando não havia cobertura de solo com a palha da cana remanescente da colheita (Durigan et al., 2004). Corroborando essas informações, Azania et al. (2002) constataram que uma camada de palha de $15 \mathrm{t} \mathrm{ha}^{-1}$ apresenta potencial de reter o herbicida imazapic, especialmente sob periodos de pouca precipitação ou irrigação.
Medeiros et al. (2004) desenvolveram experimento para avaliar a eficácia do herbicida imazapic no controle de tiririca em presença de palha de cana-de-açúcar e concluíram que, mesmo que após a aplicação do herbicida ocorra um período de seca de até 60 dias, a transposição do herbicida imazapic através da palha de cana, nas doses de 123 e $147 \mathrm{~g} \mathrm{ha}^{1}$, é altamente significativa, independentemente da quantidade de água (10 ou $20 \mathrm{~mm}$ ) aplicada após a aplicação do herbicida.

Simoni et al. (2006) relataram que, para o sulfentrazone, a presença de $20 \mathrm{t} \mathrm{ha}^{-1}$ de palha de cana-de-açúcar diminuiu a eficácia do herbicida; já o imazapic proporcionou bom desempenho tanto na ausência quanto na presença de palha, independentemente da intensidade de chuva.

Toledo et al., (2009) observaram que o herbicida Dinamic (amicarbazone) apresentou excelente eficácia no controle de corda-deviola (Ipomoea grandifolia e Merremia cissoides), leiteiro (Euphorbia heterophylla) e capim-braquiária (Brachiaria decumbens), independentemente da dose utilizada $\left(0,75\right.$ a $\left.1,50 \mathrm{~kg} \mathrm{ha}^{-1}\right)$ e do posicionamento na palha ou no solo, demonstrando assim ser uma excelente alternativa para o controle de plantas daninhas em cana-de-açúcar crua.

Oliveira \& Freitas, (2009) observaram que a quantidade de palha de $16 \mathrm{tha}^{-1}$ controlou de forma eficiente a espécie Rottboellia exaltata, independentemente da utilização de herbicidas.

Monquero et al. (2007), trabalhando com herbicidas em diversas quantidades de palha de cana-de-açúcar, observaram controle insatisfatório de Euphorbia heterophylla ao usar mais que $15 \mathrm{t} \mathrm{ha}^{-1}$ (Tabela 4). Esses autores

Tabela 4 - Controle de Euphorbia heterophylla em função de diferentes herbicidas e níveis de palha, avaliado aos 28 dias após a aplicação dos herbicidas

\begin{tabular}{|l|c|c|c|c|c|}
\hline \multirow{2}{*}{ Herbicida } & \multicolumn{5}{c|}{ Palha de cana-de-açúcar $\left(\mathrm{t} \mathrm{ha}^{-1}\right)$} \\
\cline { 2 - 6 } & 0 & 5 & 10 & 15 & 20 \\
\hline Imazapyr & $85 \mathrm{aA}^{1 /}$ & $87 \mathrm{aA}$ & $87 \mathrm{aA}$ & $80 \mathrm{aA}$ & $30 \mathrm{bC}$ \\
\hline Imazapic & $91 \mathrm{aA}$ & $91 \mathrm{aA}$ & $84 \mathrm{aA}$ & $55 \mathrm{bB}$ & $27 \mathrm{cC}$ \\
\hline Trifloxysulfuron-sodium + ametryn & $100 \mathrm{aA}$ & $100 \mathrm{aA}$ & $92 \mathrm{aA}$ & $90 \mathrm{aA}$ & $60 \mathrm{aB}$ \\
\hline Diuron + hexazinone & $100 \mathrm{aA}$ & $100 \mathrm{aA}$ & $95 \mathrm{aA}$ & $30 \mathrm{cB}$ & $37 \mathrm{bC}$ \\
\hline
\end{tabular}

1/ Médias seguidas da mesma letra, maiúscula na coluna e minúscula na linha, não diferem entre si a 5\% de probabilidade pelo teste de Tukey. Monqueiro et al. (2007). 
Tabela 5 - Número de plantas por vaso de Ipomoea grandifolia I. hederifolia e I. quamoclit aos 32 dias após a semeadura, submetidas a quatro quantidades de palha de cana-crua sobre o solo

\begin{tabular}{|c|c|c|c|}
\hline Palha $\left(\mathrm{t} \mathrm{ha}^{-1}\right)$ & I. grandifolia & I. hederifolia & I. quamoclit \\
\hline 0 & $16,25 \mathrm{a}^{\mathrm{1}^{-}}$ & $13,50 \mathrm{a}$ & $33,75 \mathrm{ab}$ \\
\hline 5 & $11,75 \mathrm{a}$ & $8,25 \mathrm{a}$ & $40,50 \mathrm{ab}$ \\
\hline 10 & $16,25 \mathrm{a}$ & $8,75 \mathrm{a}$ & $45,25 \mathrm{a}$ \\
\hline 15 & $15,50 \mathrm{a}$ & $8,50 \mathrm{a}$ & $34,50 \mathrm{ab}$ \\
\hline
\end{tabular}

1/ Médias seguidas pela mesma letra não diferem entre si na coluna pelo teste de Tukey a $5 \%$.

verificaram que a cobertura do solo com 15 e $20 \mathrm{t} \mathrm{ha}^{-1}$ de palha, tanto nas parcelas com e sem aplicação de herbicidas, proporcionou redução na emergência de E. heterophylla. Para essas quantidades de palha, Velini \& Negrisoli (2000) verificaram que não houve diferenças significativas entre os tratamentos sem (testemunha) e quando se utilizaram herbicidas (imazapic, imazapyr e trifloxysulfuron-sodium + ametryn), possivelmente pela alta interceptação do herbicida pela palha, que pode ser de aproximadamente $99,5 \%$ da calda aplicada.

Tofoli et al., (2009) trabalhando com o herbicida tebuthiuron aplicado sobre a palhada de cana-crua observaram que pequenas quantidades de palha foram capazes de interceptar praticamente toda a calda de aplicação, sendo que, a primeira chuva e os primeiros $20 \mathrm{~mm}$ de chuva foram fundamentais no processo de carregamento do tebuthiuron para o solo, independentemente da quantidade de palha; e o carregamento do tebuthiuron para o solo foi reduzido com o aumento do intervalo entre a aplicação e a primeira chuva.

Carbonari et al., (2010) observatram que de maneira geral, o herbicida clomazone + hexazinona promoveu excelentes resultados de controle para todas as espécies estudadas quando aplicado sobre, sob ou na ausência de palha de cana-de-açúcar. Os mesmo autores concluíram que o sistema de cultivo da cultura (solo com ou sem palha) não interferiu de maneira significativa para a maioria das plantas daninhas. No entanto, observaram tendência de redução nos níveis de controle para períodos acima de 60 dias sem ocorrência de chuvas, principalmente sobre a palha e o solo,
Tabela 6 - Número de plantas por vaso de Brachiaria decumbens, Digitaria horizontalis e Sida spinosa aos 32 dias após a semeadura, submetidas a quatro quantidades de palha de cana-crua sobre o solo

\begin{tabular}{|c|c|c|c|}
\hline Palha $\left(\mathrm{t} \mathrm{ha}^{-1}\right)$ & B. decumbens & D. horizontalis & S. spinosa \\
\hline 0 & $17,75 \mathrm{a}^{\mathrm{1}^{/}}$ & $57,50 \mathrm{a}$ & $7,25 \mathrm{a}$ \\
\hline 5 & $9,75 \mathrm{~b}$ & $51,00 \mathrm{a}$ & $0,25 \mathrm{~b}$ \\
\hline 10 & $8,50 \mathrm{~b}$ & $20,50 \mathrm{~b}$ & $0,50 \mathrm{~b}$ \\
\hline 15 & $7,00 \mathrm{~b}$ & $9,50 \mathrm{~b}$ & $0,00 \mathrm{~b}$ \\
\hline
\end{tabular}

${ }^{1 /}$ Médias seguidas pela mesma letra não diferem entre si na coluna pelo teste de Tukey a $5 \%$.

indicando que existe degradação dos produtos quando submetidos a períodos extensos de exposição na superfície da palha ou solo sem ocorrência de chuvas para que ocorra a distribuição deles no perfil do solo.

Pesquisas sobre a lixiviação e ação dos herbicidas através da palha de cana-de-açúcar deixada sobre a superficie do solo têm sido realizadas. Para Cavenaghi et al. (2007), com o aumento da quantidade de palha de cana sobre o solo, ocorre diminuição da quantidade do amicarbazone lixiviado pela chuva, principalmente na quantidade de $20 \mathrm{t} \mathrm{ha}^{-1}$.

Durigan et al. (2004), ao trabalharem com controle químico de tiririca com e sem cobertura do solo, observaram redução na emergência de plantas aos 45 e 90 dias na presença de palhada. Segundo esses autores, a presença da palha esta sendo forte aliada no controle, porém está longe de ser a solução para evitar a brotação, emergência e convivência, sobretudo da tiririca, com a cultura.

A redução nas chances de sobrevivência das plântulas com pequenas quantidades de reservas nos diásporos (Pitelli \& Durigan, 2001) e a redução da amplitude térmica (Egley \& Duke, 1985; Velini \& Negrisoli, 2000), proporcionadas pelas coberturas mortas, não parecem ser as melhores teorias para explicar as reduções nas populações de tiririca. No entanto, a quantidade e a qualidade da luz que atravessa pelos interstícios da palha (Zimdahl, 1993) e a possibilidade de efeitos alelopáticos por substâncias produzidas e liberadas (Lorenzi, 1993) podem constituir-se nas principais características relacionadas à redução. 
Durigan et al. (2004) observaram que as diversas alternativas de controle ocasionam prejuízos ou benefícios à ação de certos herbicidas, em função da presença ou ausência de palha, e que alguns deles, como o imazapic e o sulfentrazone, tiveram seu desempenho afetado pela presença da palha em ambas as avaliações, sendo os únicos a manterem controle superior a $80 \%$, até 90 dias, quando na ausência desta. Esses autores relataram também que a mistura pronta, independentemente da dose, proporcionou controle regular, enquanto para o halosulfuron ocasionou elevada redução no controle com o passar do tempo, evidenciando a ausência de efeito residual.

\section{Impactos ambientais}

A utilização de grandes áreas com plantio de cana-de-açúcar leva ao emprego de quantidades expressivas de insumos agrícolas; entre estes, o elevado uso de herbicidas para o controle de plantas daninhas pode alterar a qualidade físico-química e biológica do solo (Reis et al., 2008a).

Algumas técnicas têm-se mostrado eficientes na avaliação dos impactos dos cultivos agrícolas sobre o ambiente, a exemplo do emprego de indicadores microbiológicos para averiguação da qualidade do solo. Normalmente, pequenas alterações na qualidade do solo estão associadas a mudanças em suas propriedades microbiológicas, as quais apresentam alta sensibilidade a perturbações advindas do manejo (Tótola \& Chaer, 2002).

A aplicação de agrotóxicos interfere positiva ou negativamente na atividade dos organismos do solo, propiciando a metabolização deles pelos organismos e a capacidade de os produtos intoxicarem a biota do solo, respectivamente (Vivian et al., 2006).

Verificando o impacto da aplicação de herbicidas pós-emergentes na cana-de-açúcar sobre a atividade microbiana do solo, Reis et al. (2008b) relataram que o herbicida 2,4-D reduziu a densidade populacional bacteriana e fúngica do solo rizosférico, sendo considerado produto tóxico à microbiota do solo, diminuindo a sua qualidade. Corroborando essas informações, Reis et al. (2008c) verificaram que o ametryn isolado e em mistura com trifloxysulfuron-sodium proporcionou condições estressantes para os microrganismos em aplicações em pós-emergência da cultura, ao aumentarem os valores do quociente metabólico do solo $\left(\mathrm{qCO}_{2}\right)$.

De acordo com Velini \& Negrisoli (2000), outro possível impacto ambiental negativo decorrente do uso de herbicidas em cana-crua está associado à formação de microcanais de drenagem vertical, formados pela palhada sobre o solo, podendo eles facilitar a lixiviação de herbicidas, aumentando o risco de contaminação de lençóis freáticos. Além disso, a palha sobre o solo impede a penetração de luz solar, reduzindo a intensidade de degradação de herbicidas, sobretudo aqueles utilizados na cultura e que são decompostos pela luz, como ametryn, trifloxysulfuron-sodium e diuron (Rodrigues \& Almeida, 2005).

Entretanto, a colheita da cana-de-açúcar sem queima deixa sobre o solo uma espessa camada de palha, essa muito importante no manejo das plantas daninhas, sendo retratada como barreira física à penetração de luz solar sobre o solo, impedindo a germinação de espécies consideradas fotoblásticas positivas, isto é, espécies que necessitam de luz para sua germinação. Ademais, a palha sobre o solo produz aleloquímicos, que podem alterar, de forma direta ou indireta, a germinação, o crescimento e o desenvolvimento de algumas plantas daninhas (Rice, 1984; Pitelli, 1985).

De acordo com o exposto, o controle das plantas daninhas no ambiente de colheita de cana-crua é dependente da quantidade, composição e periodicidade da palha, sendo determinante na composição da flora infestante, e a eficiência do controle das espécies infestantes se dá função principalmente do tempo de permanência desses resíduos na área. Desse modo, com o uso do sistema de colheita de cana-crua ocorre menor dependência do uso de herbicidas e diminuição dos prováveis riscos de degradação e contaminação do meio ambiente.

O sistema de cultivo de cana-crua representa uma importante mudança no manejo de plantas daninhas. Nele, a colheita com a deposição de palha sobre o solo proporciona mudança da população de plantas daninhas, favorecendo espécies com maior capacidade 
de germinação sob uma espessa cobertura de palha, e retém alguns herbicidas, diminuindo a sua eficácia. Entretanto, a palhada sobre o solo impede a germinação e o estabelecimento de espécies com poucas reservas armazenadas na semente em função dos efeitos físicos e/ou alelopáticos, atuando no manejo integrado de espécies daninhas, com diminuição da dependência de herbicidas, e melhorando a qualidade do solo.

\section{AGRADECIMENTOS}

Os autores agradecem a FAPEMIG, pelo apoio concedido.

\section{LITERATURA CITADA}

ARÉVALO, R.A. Manejo de plantas daninhas em áreas de colheita de cana-crua. STAB, v. 16, n. 4, p. 26-28, 1998.

AZANIA, A. A. P. M. et al. Interferência da palha de cana-deaçúcar (Saccharum spp.) na emergência de espécies de plantas daninhas da família Convolvulaceae. Planta Daninha, v. 20, n. 2, p. 207-212, 2002.

BARBOSA, V. Cultivo de soqueira, adubação e reforma de canaviais sob o sistema de cana crua. In: SEMANA DA CANA-DE-AÇÚCAR DE PIRACICABA - SECAPI, 2., 1997, Piracicaba. Anais... Piracicaba: 1997. p. 52-54.

CARBONARI, C. A. et al. Efeitos de períodos de permanência de clomazone + hexazinona no solo e na palha de cana-de-açúcar antes da ocorrência de chuvas na eficácia de controle de plantas daninhas. Planta daninha, v. 28, n. 1, p. 197-205, 2010.

CAVENAGHI, A. L. et al. Dinâmica do herbicida amicarbazone (Dinamic $^{\circledR}$ ) aplicado sobre palha de cana-de-açúcar (Saccharum officinarum). Planta Daninha, v. 25, n. 4, p. 831-837, 2007.

CORREIA, N. M.; DURIGAN, J. C. Emergência de plantas daninhas em solo coberto com palha de cana-de-açúcar. Planta Daninha, v. 2, n. 1, p. 11-17, 2004.

CORREIA, N. M.; REZENDE, P. M. Manejo integrado de plantas daninhas na cultura da soja. Lavras: UFLA, 2002. 55 p. (Boletim Agropecuário, 51)

DURIGAN, J. C.; TIMOSSI, P. C.; LEITE, G. J. Controle químico da tiririca (Cyperus rotundus), com e sem cobertura do solo pela palha de cana-de-açúcar. Planta Daninha, v. 22, n. 1, p. 127-135, 2004.

EGLEY, G. H.; DUKE, S. Physiology of weed seed dormancy and germination. In: DUKE, S. O. Weed physiology. I. Reproduction and ecophysiology. Boca Raton: CRC Press, 1985. p. $27-64$.
GRAVENA, R. et al. Controle de plantas daninhas através da palha de cana-de-açúcar associada à mistura dos herbicidas trifloxysulfuron-sodium + ametrina. Planta Daninha, v. 22, n. 3, p. 419-427, 2004.

\section{INSTITUTO BRASILEIRO DE GEOGRAFIA E}

ESTATÍSTICA - IBGE. Disponível em: <www.ibge.gov.br/ home/estatistica/indicadores/agropecuaria $>$. Acesso em: 21 de nov. de 2009.

KUVA, M. A. et al. Períodos de interferência das plantas daninhas na cultura da cana-de-açúcar. III - Capim-braquiária (Brachiaria decumbens) e capim-colonião (Brachiaria decumbens). Planta Daninha, v. 21, n. 1, p. 37-44, 2003.

KUVA, M. A. et al. Banco de sementes de plantas daninhas e sua correlação com a flora estabelecida no agroecossistema cana-crua. Planta Daninha, v. 26, n. 4, p. 735-744, 2008.

LORENZI, H. Efeito da palha da cana no controle das plantas daninhas. In: CONGRESSO BRASILEIRO DE

HERBICIDAS E PLANTAS DANINHAS, 19., 1993, Londrina. Resumos... Londrina: Sociedade Brasileira da Ciência das Plantas Daninhas, 1993. p. 28-29.

MACIEL, C. D. G. et al. Eficiência e seletividade dos herbicidas trifloxysulfuron-sodium + ametryne e hexazinone + diuron em função da tecnologia de aplicação e do manejo mecânico da palha de cana-de-açúcar na linha de plantio. Planta Daninha, v. 26, n. 3, p. 665-676, 2008.

MARTINS, D. et al. Emergência em campo de dicotiledôneas infestantes em solo coberto com palha de cana-de-açúcar. Planta Daninha, v. 17, n. 1, p. 151-161, 1999.

MASCARENHAS, M. H. T. et al. Eficácia do halosulfuron no controle de tiririca (Cyperus rotundus) na cultura da canade-açúcar. Planta Daninha, v. 13, n. 2, p. 69-80, 1995.

MEDEIROS, D.; CHRISTOFFOLETI, P. J. Efeito da palha de cana-de-açúcar em áreas de colheita mecanizada sem queima sobre a infestação de plantas daninhas e eficácia de herbicidas. In: PRADO, R.; JORRÍN, J. V. Uso de herbicidas en la agricultura del siglo XXI. Córdoba: Universidad de Córdoba, 2001. p. 599-605

MEDEIROS, D. et al. Eficácia do herbicida imazapic no controle de tiririca (Cyperus rotundus) em presença de palha de cana-de-açúcar. In: CONGRESSO BRASILEIRO DA CIÊNCIA DAS PLANTAS DANINHAS, 24., 2004, São Pedro. Anais... São Pedro: Sociedade Brasileira da Ciência das Plantas Daninhas, 2004. CD-ROM.

MEDINA MELENDEZ, J. A. Efeito da cobertura do solo no controle de plantas daninhas na cultura do pepino (Cucumis sativus L.). 1990. 104 f. Dissertação (Mestrado em Fitotecnia) - Escola Superior de Agricultura "Luiz de Queiroz", Piracicaba, 1990 
MONQUERO, P. A. et al. Mapas de infestação de plantas daninhas em diferentes sistemas de colheita da cana-de-açúcar. Planta Daninha, v. 26, n. 1, p. 47-55, 2008.

MONQUERO, P. A. et al. Eficácia de herbicidas em diferentes quantidades de palha de cana-de-açúcar no controle de Euphorbia heterophylla. Planta Daninha, v. 25, n. 3, p. 613-619, 2007.

NÚÑEZ, O.; SPAANS, E. Evaluation of green-cane harvesting and crop management with a trash-blanket. Sugar Technol., v. 10, n. 1, p. 29-35, 2008

OLIVEIRA, A. R.; FREITAS, S. P. Levantamento fitossociológico de plantas daninhas em áreas de produção de cana-de-açúcar. Planta Daninha, v. 26, n. 1, p. 33-46, 2008 .

OLIVEIRA, A. R.; FREITAS, S. P. Palha de cana-de-açúcar associada ao herbicida trifloxysulfuron sodium + ametryn no controle de Rottboellia exaltata. Bragantia, v. 68, n. 1, p. 187-194, 2009.

OZEKI, Y., KUNZ, R., RESENDE, P. Avaliação e sugestões para aumento de rendimento operacional dos pulverizadores. STAB, v. 10, n. 6, p. 31-35, 1992.

PITELLI, R. A. Interferência de plantas daninhas em culturas agrícolas. Inf. Agropec., v. 11, n. 129, p. 16-27, 1985

PITELLI, R. A.; DURIGAN, J. C. Ecologia das plantas daninhas no sistema plantio direto. In: ROSSELLO, R. D. Siembra directa en el cono sur. Montevideo: PROCISUR, 2001. p. 203-210.

PROCÓPIO, S. O. et al. Manejo de plantas daninhas na cultura da cana-de-açúcar. Viçosa, MG: Universidade Federal de Viçosa, 2003. 150 p.

REIS, M. R. et al. Dinâmica de nutrientes em tecidos foliares de cana-de-açúcar após aplicação de herbicidas.

Planta Daninha, v. 26, n. 2, p. 323-331, 2008c.

REIS, M. R. et al. Ação de herbicidas sobre microrganismos solubilizadores de fosfato inorgânico em solo rizosférico de cana-de-açúcar. Planta Daninha, v. 26, n. 2, p. 331-341, 2008 b.

REIS, M. R. et al. Dinâmica de nutrientes em tecidos foliares de cana-de-açúcar após aplicação de herbicidas.

Planta Daninha, v. 26, n. 1, p. 175-184, 2008a.
RICE, E. L. Allelopathy. New York: Academic Press, 1984. $422 \mathrm{p}$

RODRIGUES, B. N.; ALMEIDA, F. R. Guia de herbicidas 5.ed. Londrina: Edição dos Autores, 2005. 591 p.

SILVA, J. R. V.; COSTA, N. V.; MARTINS, D. Efeitos da palhada de cultivares de cana-de-açúcar na emergência da Cyperus rotundus. Planta Daninha, v. 21, n. 3, p. 375-380, 2003.

SIMONI, F. et al. Eficácia de imazapic e sulfentrazone sobre Cyperus rotundus em diferentes condições de chuva e palha de cana-de-açúcar. Planta Daninha, v. 24, n. 4, p. 769-778, 2006.

TOFOLI, G. R. et al. Dinâmica do tebuthiuron em palha de cana-de-açúcar. Planta daninha, v. 27, n. 4, p. 815-821, 2009.

TOLEDO, E. T. et al. Green sugarcane versus burned sugarcane - results of six years in the Soconusco region of Chiapas, Mexico. Sugar Cane Intern., v. 23, n. 1, p. 20-23, 2005.

TOLEDO, R. E. B. et al. Eficácia do herbicida amicarbazone aplicado sobre a palha ou no solo no controle de plantas daninhas na cultura da cana-de-açúcar. Planta daninha, v. 27, n. 2, p. 319-326, 2009.

TÓTOLA, M. R.; CHAER, G. M. Microrganismos e processos microbiológicos como indicadores da qualidade dos solos. In: ALVAREZ V., V. H. et al. (Eds.). Tópicos em ciência do solo. Viçosa, MG: Sociedade Brasileira de Ciência do Solo, 2002. v. 2. p. 195-276.

VELINI, E. D.; NEGRISOLI, E. Controle de plantas daninhas em cana-crua. In: CONGRESSO BRASILEIRO DA CIÊNCIA DAS PLANTAS DANINHAS, 22., 2000, Foz do Iguaçu. Anais... Foz do Iguaçu: Sociedade Brasileira da Ciência das Plantas Daninhas, 2000. p. 148-164.

VELINI, E. D. et al. Avaliação da seletividade da mistura de oxyfluorfen e ametryne, aplicada em pré ou pós-emergência, a dez variedades de cana-de-açúcar (cana planta). Planta

Daninha, v. 18, p. 123-134, 2000.

VIVIAN, R. et al. Persistência de sulfentrazone em Argissolo Vermelho-Amarelo cultivado com cana-de-açúcar. Planta Daninha, v. 24, n. 4, p. 741-750, 2006.

ZIMDAHL, R. L. Fundamentals of weed science. New York: Academic Press, 1993. 450 p. 